\title{
Review
}

\section{Negative immunomodulation by parasitic infections in the human response to vaccines}

\author{
Catalina Alvarez-Larrotta ${ }^{1}$, Eliana María Arango ${ }^{1}$, Jaime Carmona-Fonseca ${ }^{1}$ \\ ${ }^{1}$ Grupo Salud y Comunidad, Facultad de Medicina, Universidad de Antioquia, Medellín, Colombia
}

\begin{abstract}
Parasitic infections are an important cause of global morbidity and mortality and are highly prevalent in "underdeveloped" countries. The presence of parasitic infections is associated with modulation of the immune system and changes in the response to bacterial and viral vaccines. The objective of this review was to compile, summarize and analyze information about immunomodulation by parasitic infections and its effects on the immune response to vaccines. We also identified the parasites most associated with immunomodulation of vaccine responses and those vaccines most affected. In addition, articles evaluating the effect of chemoprophylaxis for malaria on the immune response against vaccines were considered. The most affected vaccines are Bacillus Calmette-Guérin and bacterial polysaccharide vaccines. Malaria is the infection most associated with decreased response to vaccines; however, there are discordant results. Chemoprophylaxis for malaria did not change the immune response to vaccination. While parasitic infections can alter the immune response to vaccination, it is important to clarify the discrepancies and establish the mechanisms.
\end{abstract}

Key words: parasites; vaccines; immunomodulation; Plasmodium; helminths.

J Infect Dev Ctries 2018; 12(10):812-823. doi:10.3855/jidc.10337

(Received 10 March 2018 - Accepted 28 September 2018)

Copyright (C) 2018 Alvarez-Larrotta et al. This is an open-access article distributed under the Creative Commons Attribution License, which permits unrestricted use, distribution, and reproduction in any medium, provided the original work is properly cited.

\section{Introduction}

Infection and poverty are intrinsically linked problems that perpetually challenge human health. Malnutrition arises from poverty and is a major determinant of morbidity and mortality by infectious diseases. Malnutrition can determine the severity of infection, as well as the risk of death. A poor body condition weakens the immune system and increases the risk of infection, which leads to loss of appetite, and then, loss of nutrients that are used in the defense against infection. This leads to a vicious cycle with detrimental outcomes (malnutrition $\rightarrow$ immunosuppression $\rightarrow$ infection $\rightarrow$ increased malnutrition $\rightarrow$ increased immunosuppression $\rightarrow$ increased infection) $[1,2]$.

Hunger and malnutrition, with few exceptions, result from "economic poverty" [3], which affects quality of life and lifestyle [3,4]. The populations with the highest poverty, and then, with the worst living conditions, are the most affected by parasitic infections. Tropical and subtropical zones of the world have, in addition to the greatest number of poor people, the optimal natural and social conditions for the maximum spread of parasitic infections. While populations living in temperate and frigid zones also live in poverty, the natural conditions are generally inadequate to support parasites development, and these infections are absent or very scarce. Human parasites have a global distribution, but undoubtedly they reach disproportionate levels in the tropics [5-7]

In tropical zones, patients are typically infected with multiple parasitic infections at once. It is already known that parasitic infections are associated with immune tolerance [8-10], and this tolerance allows the survival of the parasite in the host and minimizes the damage [11]. This means that infections by various parasites cause a nonspecific effect on the immune response. For that reason, the susceptibility to infections increases and acquired immunity is altered by limitation of the inflammatory response, which is essential to generate the immune response [12].

The life cycle of several parasites involves an insect that operates as a vector or an animal as a reservoir (malaria, leishmaniosis, Chagas disease, trypanosomosis, filarioidosis, onchocercidosis, etc.). Vector-borne diseases account for more than $17 \%$ of all infectious diseases and cause more than 1 million of deaths every year [13]. This situation implies that natural and social conditions contribute to the reproduction and transmission of parasites and their 
vectors. Among the most prevalent parasitic diseases in the world are geohelminthosis, malaria, schistosomosis, onchocercidosis, filarioidosis and leishmaniosis. Figure 1 shows the wide territory covered by parasitic infections, and their importance in public health. It is crucial to note that in tropical areas, there is abundant diversity of parasites and the greatest risk to acquire these infections.

The parasitic infections mentioned above (except leishmaniosis) can cause chronic and asymptomatic infections and constantly stimulate the immune system, which leads to a greater modulation of the immune system, i.e. high regulation or control of the immune response [14]. In addition, multiple co-infections can occur in different endemic areas and complicate the scenario. For geohelminthosis, filarioidosis and trematodiosis, a high regulation of the immune response has been described [15-17]. This regulation is associated with tolerance to the parasitic infections, which leads to: a) limitation of the acute immune response against other pathogens; b) reduction of the antigen-specific response; and c) deficiency in the acquired immune response [15-17]. Malaria usually is an acute disease, but can also be a chronic asymptomatic infection, which is mostly associated with increased regulation of the immune response $[18,19]$.

Helminthosis (the most widely distributed parasite) is caused by extracellular parasites, and therefore is associated with a Th2 immune response. The chronicity of infection results in the constant stimulation of the immune system [20]. The Th2 response is characterized by the increase of regulatory-associated cytokines, such as interleukin-10 (IL-10) and transforming growth factor beta (TGF- $\beta$ ). These cytokines condition the differentiation of immune cells with regulatory profiles that promote tolerance in the infected subject [21]. The immune cells differentiated by these cytokines are the regulatory $\mathrm{T}$ cells (Treg) and the macrophages with alternative activation (M2). These cells induce amplification of the production of regulatory cytokines (IL-10 and TGF- $\beta$ ) and, therefore, more differentiation of these cell types [22]. Several studies have associated parasitic infections with increased IL-10 and regulatory cells [23-25]. This modulation limits the proliferation of immune effector cells such as $\mathrm{CD}^{+} \mathrm{T}, \mathrm{CD}^{+} \mathrm{T}$, and natural killer cells $(\mathrm{NK})$, which are important in vaccination and defense against other pathogens. The limitation of the effector $\mathrm{T}$ cells prevents the amplification of the immune response necessary to develop adequate immune memory [26].

Figure 1. Global epidemiology of parasitic infections according to latitude.

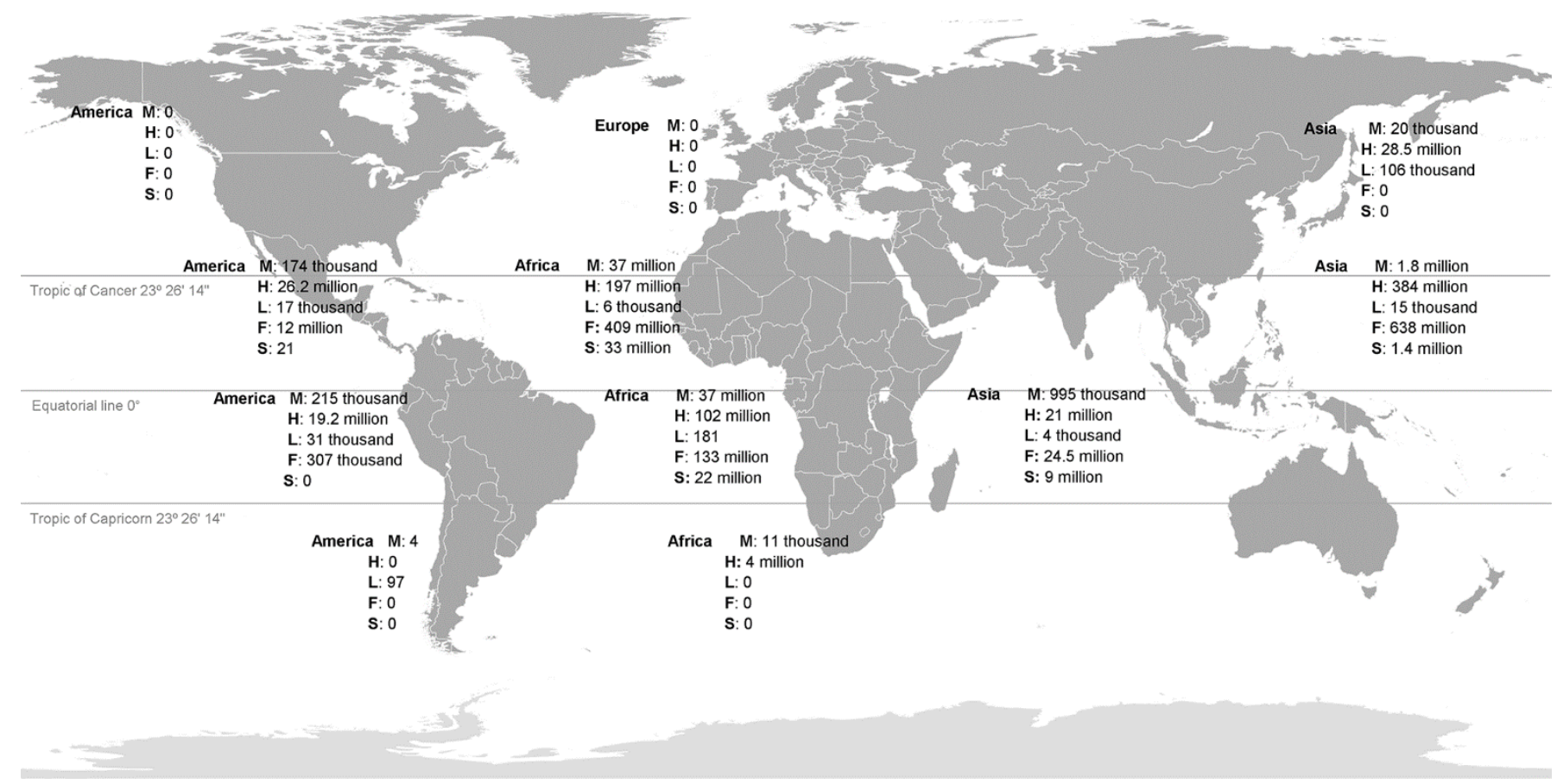

Malaria (M): number of cases reported in 2014 [71]; Geohelminthosis (H): number of children requiring preventive therapy (TP) in 2014 [72]; Leishmaniosis (L): number of cases of cutaneous and visceral Leishmaniosis reported in 2013 [73]; Filarioidosis (F): number of people requiring preventive therapy (TP) in 2014 [74]; Schistosomosis (S): Number of people treated for this disease in 2014 [75]; Image taken and modified from: https://commons.wikimedia.org/w/index.php?curid=3231806. By Frank Bennett. 
Table 1. Effect of parasitic infections on the immune response to vaccines.

\begin{tabular}{|c|c|c|c|c|c|c|c|}
\hline $\begin{array}{l}\text { Parasitic } \\
\text { infection }\end{array}$ & Reference & $\begin{array}{c}\text { Population age } \\
\text { range }\end{array}$ & $\begin{array}{l}\text { Exposition } \\
\text { factor }\end{array}$ & \multicolumn{2}{|c|}{ Average (CI) } & $\mathbf{p}$ & $\begin{array}{l}\text { Authors' } \\
\text { conclusion }\end{array}$ \\
\hline \multicolumn{8}{|c|}{ Tetanus toxoid } \\
\hline \multirow{11}{*}{ Filarioidosis } & \multirow{3}{*}{$\begin{array}{c}\text { Cooper et al., } \\
1999 \text { [33] } \\
\text { Ecuador }\end{array}$} & \multirow{3}{*}{$\begin{array}{c}\text { Subjects } \\
(5-70 \text { years old })\end{array}$} & \multirow{3}{*}{$\begin{array}{l}\text { Infection by } \\
\text { Onchocerca } \\
\text { volvulus }\end{array}$} & Study groups & $\begin{array}{l}\text { Antibody levels } \\
\text { UI/mL }\end{array}$ & \multirow{3}{*}{ NS } & \multirow{3}{*}{$\begin{array}{l}\text { Infection by } O \text {. } \\
\text { volvulus does not } \\
\text { affect the } \\
\text { generation of } \\
\text { tetanus protection. }\end{array}$} \\
\hline & & & & $\begin{array}{l}\text { Infected } \\
(\mathrm{n}=193)\end{array}$ & $\begin{array}{c}1.32(1.15- \\
1.74)\end{array}$ & & \\
\hline & & & & $\begin{array}{l}\text { Uninfected } \\
(\mathrm{n}=85)\end{array}$ & $\begin{array}{c}1.41(0.84- \\
1.44)\end{array}$ & & \\
\hline & \multirow{3}{*}{$\begin{array}{c}\text { Prost et al., } \\
1983 \text { [38] } \\
\text { Burkina Faso }\end{array}$} & \multirow{3}{*}{$\begin{array}{c}\text { Subjects } \\
(9-34 \text { years old })\end{array}$} & \multirow{3}{*}{$\begin{array}{l}\text { Infection by } \\
\text { O. volvulus }\end{array}$} & Study groups & $\begin{array}{l}\text { Antibody levels } \\
\text { UI/mL }\end{array}$ & \multirow{3}{*}{0.001} & \multirow{3}{*}{$\begin{array}{l}\text { Infection by } O \text {. } \\
\text { volvulus decreases } \\
\text { humoral immunity. }\end{array}$} \\
\hline & & & & $\begin{array}{l}\text { Infected } \\
(\mathrm{n}=28)\end{array}$ & $\begin{array}{c}0.07(0.056- \\
0.084)\end{array}$ & & \\
\hline & & & & $\begin{array}{l}\text { Uninfected } \\
(\mathrm{n}=27)\end{array}$ & $\begin{array}{c}2.41(1.93- \\
2.90)\end{array}$ & & \\
\hline & \multirow{3}{*}{$\begin{array}{l}\text { Nookala et al., } \\
2004 \text { [39] India }\end{array}$} & \multirow{3}{*}{$\begin{array}{l}\text { Subjects, adults } \\
\text { (20-66 years old) }\end{array}$} & \multirow{3}{*}{$\begin{array}{l}\text { Infection by } \\
\text { Wuchereria } \\
\text { bancrofti }\end{array}$} & Study groups & $\begin{array}{l}\text { Antibody levels } \\
\text { UI/mL }\end{array}$ & \multirow{3}{*}{0.0002} & \multirow{3}{*}{$\begin{array}{l}\text { Infection by } W \text {. } \\
\text { bancrofti altered } \\
\text { the immune } \\
\text { response against } \\
\text { tetanus toxoid. }\end{array}$} \\
\hline & & & & $\begin{array}{l}\text { Infected } \\
(\mathrm{n}=40)\end{array}$ & $149(73.5-583)$ & & \\
\hline & & & & $\begin{array}{l}\text { Uninfected } \\
(\mathrm{N}=10)\end{array}$ & $\begin{array}{c}910.2(416.5- \\
1989)\end{array}$ & & \\
\hline & \multirow[b]{2}{*}{$\begin{array}{l}\text { Malhotra et al., } \\
2015 \text { [40] Kenya }\end{array}$} & \multirow[b]{2}{*}{$\begin{array}{l}\text { Mothers/children } \\
\text { (>14 years old/ } \\
6-36 \text { months old) }\end{array}$} & \multirow{2}{*}{$\begin{array}{c}\text { Exposed in } \\
\text { utero to } \\
\text { Brugia malayi } \\
\text { or } W . \\
\text { bancrofti }\end{array}$} & $\begin{array}{l}\text { Sensitized } \\
(\mathrm{n}=167)\end{array}$ & & & $\begin{array}{l}\text { The levels of IgG } \\
\text { against tetanus }\end{array}$ \\
\hline & & & & $\begin{array}{l}\text { Unexposed } \\
(\mathrm{n}=110)\end{array}$ & NI & NS & $\begin{array}{l}\text { toxoid were not } \\
\text { affected in children } \\
\text { sensitized by } \\
\text { filariasis. }\end{array}$ \\
\hline \multirow{11}{*}{ Malaria } & \multirow{2}{*}{$\begin{array}{l}\text { Greenwood et } \\
\text { al., [35] } 1972 \\
\text { Nigeria }\end{array}$} & \multirow{2}{*}{$\begin{array}{l}\text { Children } \\
\text { (6 months-6 } \\
\text { years old) }\end{array}$} & \multirow{2}{*}{$\begin{array}{l}\text { Acute malaria } \\
\text { by } \\
\text { Plasmodium } \\
\text { falciparum }\end{array}$} & $\begin{array}{l}\text { Infected } \\
(\mathrm{n}=51)\end{array}$ & & & \multirow{2}{*}{$\begin{array}{l}\text { In children with } \\
\text { acute } P \text {. falciparum } \\
\text { malaria, a form of } \\
\text { immunosuppressio } \\
\text { n was } \\
\text { demonstrated. }\end{array}$} \\
\hline & & & & $\begin{array}{l}\text { Uninfected } \\
(\mathrm{N}=34)\end{array}$ & NI & $<0,02$ & \\
\hline & \multirow{2}{*}{$\begin{array}{c}\text { Corrigall et al., } \\
1988 \text { [49] Papua } \\
\text { New Guinea }\end{array}$} & \multirow{2}{*}{$\begin{array}{c}\text { Children } \\
\text { (8-11 years old) }\end{array}$} & \multirow{2}{*}{$\begin{array}{l}\text { Asymptomatic } \\
\text { malaria by } P \text {. } \\
\text { falciparum, } P \text {. } \\
\text { vivax and } P . \\
\text { malariae }\end{array}$} & $\begin{array}{l}\text { Infected } \\
(\mathrm{n}=51)\end{array}$ & & & \multirow{2}{*}{$\begin{array}{l}\text { Malaria did not } \\
\text { affect the immune } \\
\text { response against } \\
\text { tetanus toxoid }\end{array}$} \\
\hline & & & & $\begin{array}{l}\text { Uninfected } \\
(\mathrm{N}=34)\end{array}$ & NI & $>0,1$ & \\
\hline & \multirow{3}{*}{$\begin{array}{c}\text { Cumberland et } \\
\text { al., } 2007[36] \\
\text { Kenya }\end{array}$} & \multirow{3}{*}{$\begin{array}{l}\text { Pregnant women } \\
(>14 \text { years old })\end{array}$} & & Study groups & $\begin{array}{c}\text { Antibody levels } \\
\text { UI/mL }\end{array}$ & & IgG levels are \\
\hline & & & $\begin{array}{l}\text { Placental } \\
\text { malaria by }\end{array}$ & $\begin{array}{l}\text { Infected } \\
(\mathrm{n}=312)\end{array}$ & $\begin{array}{l}2.39(1.46- \\
4.12)\end{array}$ & NI & $\begin{array}{l}\text { Significantly low in } \\
\text { women with active- }\end{array}$ \\
\hline & & & & $\begin{array}{l}\text { Uninfected } \\
(\mathrm{n}=291)\end{array}$ & $\begin{array}{l}3.64(3.13- \\
4.23)\end{array}$ & & $\begin{array}{l}\text { chronic or past } \\
\text { placental malaria }\end{array}$ \\
\hline & & & & $\begin{array}{l}\text { Infected } \\
(\mathrm{n}=11)\end{array}$ & & & $\begin{array}{c}\text { Acute } P . \\
\text { falciparum }\end{array}$ \\
\hline & $\begin{array}{c}\text { van Riet et al., } \\
2007 \text { [50] } \\
\text { Gabon }\end{array}$ & $\begin{array}{c}\text { Children } \\
\text { (7-12 years old) }\end{array}$ & $\begin{array}{l}\text { Acute malaria } \\
\text { by } P \text {. } \\
\text { falciparum }\end{array}$ & $\begin{array}{l}\text { Uninfected } \\
(\mathrm{n}=42)\end{array}$ & NI & NI & $\begin{array}{l}\text { infection did not } \\
\text { affect the response } \\
\text { against the boosts } \\
\text { of the tetanus } \\
\text { toxoid vaccine. }\end{array}$ \\
\hline & & & & $\begin{array}{l}\text { Sensitized } \\
(\mathrm{n}=188)\end{array}$ & & & $\begin{array}{c}\text { The levels of IgG } \\
\text { against tetanus }\end{array}$ \\
\hline & $\begin{array}{l}\text { Malhotra et al., } \\
2015 \text { [40] Kenya }\end{array}$ & $\begin{array}{l}(>14 \text { years old/ } \\
6-36 \text { months old })\end{array}$ & $\begin{array}{l}\text { utero to } \\
\text { P. falciparum }\end{array}$ & $\begin{array}{l}\text { Unexposed } \\
(\mathrm{n}=179)\end{array}$ & NI & NS & $\begin{array}{l}\text { toxoid vaccine } \\
\text { were not affected in } \\
\text { children sensitized } \\
\text { by } P \text {. falciparum. }\end{array}$ \\
\hline & & Mothers/children & Exposed in & $\begin{array}{c}\text { Sensitized } \\
(\mathrm{n}=238)\end{array}$ & & & $\begin{array}{l}\text { The levels of IgG } \\
\text { against tetanus }\end{array}$ \\
\hline Schistosomosis & $\begin{array}{l}\text { Malhotra et al., } \\
2015 \text { [40] Kenya }\end{array}$ & $\begin{array}{l}(>14 \text { years old/ } \\
6-36 \text { months old })\end{array}$ & $\begin{array}{l}\text { utero to } \\
\text { Schistosoma } \\
\text { haematobium }\end{array}$ & $\begin{array}{l}\text { Unexposed } \\
(\mathrm{n}=90)\end{array}$ & NI & NS & $\begin{array}{c}\text { toxoid vaccine } \\
\text { were not affected in } \\
\text { children sensitized } \\
\text { by } S . \text { haematobium. }\end{array}$ \\
\hline
\end{tabular}


Table 1 (continued). Effect of parasitic infections on the immune response to vaccines.

\begin{tabular}{|c|c|c|c|c|c|c|c|}
\hline \multicolumn{8}{|c|}{ Diphtheria toxoid } \\
\hline $\begin{array}{l}\text { Parasitic } \\
\text { infection }\end{array}$ & Reference & $\begin{array}{l}\text { Population } \\
\text { age range }\end{array}$ & $\begin{array}{l}\text { Exposition } \\
\text { factor }\end{array}$ & \multicolumn{2}{|c|}{ Average (CI) } & p & $\begin{array}{l}\text { Author's } \\
\text { conclusion }\end{array}$ \\
\hline \multirow{3}{*}{ Filarioidosis } & \multirow{3}{*}{$\begin{array}{l}\text { Malhotra et al., } \\
2015 \text { [40] Kenya }\end{array}$} & \multirow{3}{*}{$\begin{array}{l}\text { Mothers/children } \\
(>14 \text { years old/ } \\
6-36 \text { months old })\end{array}$} & \multirow{3}{*}{$\begin{array}{l}\text { Exposed in } \\
\text { utero to } B \text {. } \\
\text { malayi or } W \text {. } \\
\text { bancrofti }\end{array}$} & Study groups & Antibody levels & \multirow{3}{*}{ NS } & \multirow{3}{*}{$\begin{array}{l}\text { The levels of IgG } \\
\text { against diphtheria } \\
\text { toxoid vaccine } \\
\text { were not affected in } \\
\text { children sensitized } \\
\text { by filariasis. }\end{array}$} \\
\hline & & & & $\begin{array}{l}\text { Sensitized } \\
(\mathrm{n}=167)\end{array}$ & NI & & \\
\hline & & & & $\begin{array}{l}\text { Unexposed } \\
(\mathrm{n}=110)\end{array}$ & NI & & \\
\hline \multirow[b]{2}{*}{ Malaria } & \multirow[b]{2}{*}{$\begin{array}{l}\text { Malhotra et al., } \\
2015 \text { [40] Kenya }\end{array}$} & \multirow[b]{2}{*}{$\begin{array}{l}\text { Mothers/children } \\
(>14 \text { years old/ } \\
6-36 \text { months old })\end{array}$} & \multirow[b]{2}{*}{$\begin{array}{l}\text { Exposed in } \\
\text { utero to } \\
P . \text { falciparum }\end{array}$} & $\begin{array}{l}\text { Sensitized } \\
(\mathrm{n}=188)\end{array}$ & & & $\begin{array}{c}\text { In children } \\
\text { sensitized by } P \text {. }\end{array}$ \\
\hline & & & & $\begin{array}{l}\text { Unexposed } \\
(\mathrm{n}=179)\end{array}$ & NI & NS & $\begin{array}{c}\text { falciparum, } \\
\text { decreased levels of } \\
\text { IgG against } \\
\text { diphtheria toxoid } \\
\text { vaccine were } \\
\text { observed. }\end{array}$ \\
\hline \multirow[b]{2}{*}{ Schistosomosis } & \multirow[b]{2}{*}{$\begin{array}{l}\text { Malhotra et al., } \\
2015 \text { [40] Kenya }\end{array}$} & \multirow[b]{2}{*}{$\begin{array}{l}\text { Mothers/children } \\
(>14 \text { years old/ } \\
6-36 \text { months old })\end{array}$} & \multirow{2}{*}{$\begin{array}{l}\text { Exposed in } \\
\text { utero to } \\
S . \\
\text { haematobium }\end{array}$} & $\begin{array}{l}\text { Sensitized } \\
(\mathrm{n}=238)\end{array}$ & \multirow[b]{2}{*}{ NI } & \multirow[b]{2}{*}{ NS } & \multirow{2}{*}{$\begin{array}{l}\text { The levels of IgG } \\
\text { against diphtheria } \\
\text { toxoid vaccine } \\
\text { were not affected in } \\
\text { children sensitized } \\
\text { by } S \text {. haematobium. }\end{array}$} \\
\hline & & & & $\begin{array}{l}\text { Unexposed } \\
\quad(\mathrm{n}=90)\end{array}$ & & & \\
\hline \multicolumn{8}{|c|}{ BCG } \\
\hline $\begin{array}{l}\text { Parasitic } \\
\text { infection }\end{array}$ & $\begin{array}{l}\text { Author and } \\
\text { place }\end{array}$ & $\begin{array}{c}\text { Population } \\
\text { Age range }\end{array}$ & $\begin{array}{l}\text { Exposition } \\
\text { factor }\end{array}$ & \multicolumn{2}{|c|}{ Average (CI) } & $\mathbf{p}$ & $\begin{array}{l}\text { Author's } \\
\text { conclusion }\end{array}$ \\
\hline \multirow{6}{*}{ Geohelminthosis } & \multirow{3}{*}{$\begin{array}{c}\text { Elias D et al., } \\
2001 \text { [51] } \\
\text { Ethiopia }\end{array}$} & \multirow{3}{*}{$\begin{array}{c}\text { Students } \\
(18-24 \text { years old })\end{array}$} & \multirow{3}{*}{$\begin{array}{l}\text { Antihelmintic } \\
\text { treatment }\end{array}$} & Study groups & IFN $\gamma$ levels & \multirow{3}{*}{0.04} & \multirow{3}{*}{$\begin{array}{l}\text { The use of } \\
\text { antihelmintics } \\
\text { potentiated the } \\
\text { immune response } \\
\text { against BCG } \\
\text { vaccine. }\end{array}$} \\
\hline & & & & $\begin{array}{l}\text { Albendazole } \\
\quad(\mathrm{n}=29)\end{array}$ & $\begin{array}{c}170 \mathrm{pg} / \mathrm{mL} \\
(136-204 \\
\mathrm{pg} / \mathrm{mL})\end{array}$ & & \\
\hline & & & & $\begin{array}{l}\text { Placebo } \\
(\mathrm{n}=31)\end{array}$ & $\begin{array}{c}70 \mathrm{pg} / \mathrm{mL} \\
(56-84 \mathrm{pg} / \mathrm{mL})\end{array}$ & & \\
\hline & \multirow{3}{*}{$\begin{array}{l}\text { Lule et al., } 2015 \\
\text { [52] Uganda }\end{array}$} & \multirow{3}{*}{$\begin{array}{c}\text { Children } \\
(1-5 \text { years old })\end{array}$} & \multirow{3}{*}{$\begin{array}{l}\text { Infection with } \\
\text { hookworm }\end{array}$} & Study groups & IFN $\gamma$ levels & \multirow{3}{*}{ NI } & \multirow{3}{*}{$\begin{array}{c}\text { Geohelminth } \\
\text { infection was } \\
\text { associated with a } \\
\text { decrease in IFN } \gamma \\
\text { after stimulation } \\
\text { with } M \text {. } \\
\text { tuberculosis in } \\
\text { vitro. }\end{array}$} \\
\hline & & & & Infected & $\begin{array}{c}179 \mathrm{pg} / \mathrm{mL} \\
(143.5-214.8 \\
\mathrm{pg} / \mathrm{mL})\end{array}$ & & \\
\hline & & & & Uninfected & $\begin{array}{c}123 \mathrm{pg} / \mathrm{mL} \\
(98.4-147.6 \\
\mathrm{pg} / \mathrm{mL})\end{array}$ & & \\
\hline & & & & Study groups & IFN $\gamma$ levels & & Asymptomatic \\
\hline & Lule et al., 2015 & Children $(1-5$ & Asymptomatic & Infected & $\begin{array}{c}174 \mathrm{pg} / \mathrm{mL} \\
(139.2-208.8 \\
\mathrm{pg} / \mathrm{mL})\end{array}$ & NI & $\begin{array}{c}\text { malaria was } \\
\text { associated with } \\
\text { decreased IFN } \gamma\end{array}$ \\
\hline Malaria & & & & Uninfected & $\begin{array}{c}82 \mathrm{pg} / \mathrm{mL} \\
(65.6-98.4 \\
\mathrm{pg} / \mathrm{mL})\end{array}$ & & $\begin{array}{l}\text { after stimulation } \\
\text { with } M \text {. } \\
\text { tuberculosis }\end{array}$ \\
\hline vialaria & & & & Study groups & $\begin{array}{c}\text { T cells } \\
\text { CD4+IFN+ }\end{array}$ & & Placental malaria \\
\hline & $\begin{array}{l}\text { Walther et al., } \\
2012 \text { [53] }\end{array}$ & $\begin{array}{c}\text { Children } \\
\text { (Newborn -12 }\end{array}$ & Placental & $\begin{array}{c}\text { Infected } \\
(\mathrm{n}=7)\end{array}$ & $\begin{array}{c}0.007 \% \\
(0.002-0.007 \%)\end{array}$ & 0.026 & $\begin{array}{l}\text { generated a weak } \\
\text { response of IFN } \gamma \text { to }\end{array}$ \\
\hline & Gambia & months old) & malaria & $\begin{array}{l}\text { Uninfected } \\
\quad(\mathrm{n}=28)\end{array}$ & $\begin{array}{c}0.000 \% \\
(0.000-0.002 \\
\%)\end{array}$ & & $\begin{array}{l}\text { tuberculin at } 12 \\
\text { months of age. }\end{array}$ \\
\hline & & & & Study groups & Tuberculin & & \\
\hline Schistosomosis & Badawy et al. & Children & $\begin{array}{l}\text { Infection by } S \text {. } \\
\text { mansoni or } W \text {. }\end{array}$ & $\begin{array}{c}\text { Infected }(\mathrm{n}= \\
63)\end{array}$ & $\begin{array}{l}<5 \mathrm{~mm}: 33 \\
\text { children }\end{array}$ & 0.000 & The infection was \\
\hline and Filarioidosis & & (6 months) & bancrofti & $\begin{array}{l}\text { Uninfected } \\
(\mathrm{n}=187)\end{array}$ & $\begin{array}{l}<5 \mathrm{~mm}: 22 \\
\text { children }\end{array}$ & & $\begin{array}{l}\text { lower response to } \\
\text { tuberculin. }\end{array}$ \\
\hline
\end{tabular}


Table 1 (continued). Effect of parasitic infections on the immune response to vaccines.

\begin{tabular}{|c|c|c|c|c|c|c|c|}
\hline \multicolumn{8}{|c|}{ Bacterial polysaccharides } \\
\hline $\begin{array}{l}\text { Parasitic } \\
\text { infection }\end{array}$ & Reference & $\begin{array}{l}\text { Population } \\
\text { Age range }\end{array}$ & $\begin{array}{l}\text { Exposition } \\
\text { factor }\end{array}$ & \multicolumn{2}{|c|}{ Average $(\mathrm{CI})^{\mathrm{a}}$} & p & $\begin{array}{c}\text { Author's } \\
\text { conclusion }\end{array}$ \\
\hline \multirow{10}{*}{ Malaria } & \multirow{3}{*}{$\begin{array}{l}\text { Williamson et } \\
\text { al., } 1978 \text { [55] } \\
\text { Nigeria }\end{array}$} & \multirow{3}{*}{$\begin{array}{c}\text { Children } \\
\text { (6 months - } 6 \\
\text { years old })\end{array}$} & \multirow{3}{*}{$\begin{array}{l}\text { Malaria by } P \text {. } \\
\text { falciparum }\end{array}$} & Study groups & Antibody titers & \multirow{3}{*}{$\begin{array}{l}\text { S. typhi } \\
<\mathbf{0 . 0 1} \\
\text { Mening. } \\
<\mathbf{0 . 0 0 1}\end{array}$} & \multirow{3}{*}{$\begin{array}{c}\text { conclusion } \\
\text { Malaria was } \\
\text { associated with } \\
\text { decreased titers of } \\
\text { antibodies against } \\
\text { S. typhi and group } \\
\text { C meningococcal } \\
\text { polysaccharide } \\
\text { when the vaccine } \\
\text { was administered at } \\
\text { the time of } \\
\text { infection. }\end{array}$} \\
\hline & & & & $\begin{array}{l}\text { Infected } \\
(\mathrm{n}=79)\end{array}$ & $\begin{array}{c}\text { S. typhi: } 2.1 \\
\text { (log2) } \\
\text { Meningococcal: } \\
3.1(\log 2)\end{array}$ & & \\
\hline & & & & $\begin{array}{l}\text { Uninfected } \\
(\mathrm{n}=40)\end{array}$ & $\begin{array}{c}\text { S. typhi: } 1.4 \\
(\log 2) \\
\text { Meningococcal: } \\
.3 .4(\log 2)\end{array}$ & & \\
\hline & & & & $\begin{array}{l}\text { Infected } \\
(\mathrm{n}=316)\end{array}$ & \multirow[b]{2}{*}{ NI } & \multirow[b]{2}{*}{$<0.02$} & $\begin{array}{l}\text { The antibody } \\
\text { response against }\end{array}$ \\
\hline & $\begin{array}{l}\text { Greenwood et } \\
\text { al., } 1980[56] \\
\text { Nigeria }\end{array}$ & $\begin{array}{l}\text { Subjects } \\
\text { (all ages) }\end{array}$ & $\begin{array}{l}\text { Asymptomatic } \\
\text { malaria by } \\
\text { P. falciparum }\end{array}$ & $\begin{array}{l}\text { Uninfected } \\
\quad(\mathrm{n}=44)\end{array}$ & & & $\begin{array}{l}\text { meningococcal } \\
\text { polysaccharide was } \\
\text { lower in cases with } \\
\text { high parasitaemia } \\
\text { within each age } \\
\text { group }\end{array}$ \\
\hline & \multirow{3}{*}{$\begin{array}{l}\text { Usen et al., } \\
2000 \text { [57] } \\
\text { Gambia }\end{array}$} & \multirow{3}{*}{$\begin{array}{c}\text { Children } \\
\text { (12-30 months } \\
\text { old) }\end{array}$} & \multirow{3}{*}{$\begin{array}{l}\text { Malaria by } P \text {. } \\
\text { falciparum }\end{array}$} & Study groups & Antibody levels & \multirow{3}{*}{$<0.001$} & \multirow{3}{*}{$\begin{array}{c}\text { Infected children } \\
\text { with P. falciparum } \\
\text { had lower levels of } \\
\text { antibodies against } \\
\text { Haemophilus } \\
\text { influenzae type B. }\end{array}$} \\
\hline & & & & $\begin{array}{l}\text { Infected } \\
(\mathrm{n}=57\end{array}$ & $\begin{array}{c}6.3 \mu \mathrm{g} / \mathrm{mL} \\
(0.07-285 \\
\mu \mathrm{g} / \mathrm{mL})\end{array}$ & & \\
\hline & & & & $\begin{array}{l}\text { Uninfected } \\
\qquad(\mathrm{n}=60)\end{array}$ & $\begin{array}{c}23 \mu \mathrm{g} / \mathrm{mL} \\
(0.36-555 \\
\mu \mathrm{g} / \mathrm{mL})\end{array}$ & & \\
\hline & \multirow[b]{2}{*}{$\begin{array}{l}\text { Malhotra et al., } \\
2015 \text { [40] Kenya }\end{array}$} & \multirow[b]{2}{*}{$\begin{array}{l}\text { Mothers/children } \\
(>14 \text { years old/ } \\
6-36 \text { months old })\end{array}$} & \multirow[b]{2}{*}{$\begin{array}{l}\text { Exposed in } \\
\text { utero to } P \text {. } \\
\text { falciparum }\end{array}$} & $\begin{array}{l}\text { Sensitized } \\
(\mathrm{n}=188)\end{array}$ & & & $\begin{array}{l}\text { Children sensitized } \\
\text { by } P \text {. falciparum }\end{array}$ \\
\hline & & & & $\begin{array}{l}\text { Unexposed } \\
(\mathrm{n}=179)\end{array}$ & NI & 0.005 & $\begin{array}{l}\text { had significantly } \\
\text { lower Haemophilus } \\
\text { influenzae type B } \\
\text { specific IgG levels. }\end{array}$ \\
\hline \multirow[b]{2}{*}{ Filarioidosis } & \multirow[b]{2}{*}{$\begin{array}{l}\text { Malhotra et al., } \\
2015 \text { [40] Kenya }\end{array}$} & \multirow[b]{2}{*}{$\begin{array}{l}\text { Mothers/children } \\
(>14 \text { years old/ } \\
6-36 \text { months old })\end{array}$} & \multirow{2}{*}{$\begin{array}{l}\text { Exposed in } \\
\text { utero to } \\
\text { B. malayi or } \\
\text { W. bancrofti }\end{array}$} & $\begin{array}{l}\text { Sensitized } \\
(\mathrm{n}=167)\end{array}$ & & & $\begin{array}{l}\text { Children sensitized } \\
\text { by filarioidosis had }\end{array}$ \\
\hline & & & & $\begin{array}{l}\text { Unexposed } \\
(\mathrm{n}=110)\end{array}$ & NI & 0.007 & $\begin{array}{c}\text { significantly lower } \\
\text { Haemophilus } \\
\text { influenzae type B } \\
\text { specific IgG levels. }\end{array}$ \\
\hline \multirow[b]{2}{*}{ Schistosomosis } & \multirow[b]{2}{*}{$\begin{array}{l}\text { Malhotra et al., } \\
2015 \text { [40] Kenya }\end{array}$} & \multirow[b]{2}{*}{$\begin{array}{l}\text { Mothers/children } \\
(>14 \text { years old/ } \\
6-36 \text { months old })\end{array}$} & \multirow[b]{2}{*}{$\begin{array}{l}\text { Exposed in } \\
\text { utero to } S \text {. } \\
\text { haematobium }\end{array}$} & $\begin{array}{l}\text { Sensitized } \\
(\mathrm{n}=238)\end{array}$ & & & \multirow{2}{*}{$\begin{array}{c}\text { Children sensitized } \\
\text { by S. haematobium } \\
\text { had significantly } \\
\text { lower Haemophilus } \\
\text { influenzae type B } \\
\text { specific IgG levels. }\end{array}$} \\
\hline & & & & $\begin{array}{l}\text { Unexposed } \\
(n=90)\end{array}$ & NI & 0.034 & \\
\hline
\end{tabular}


Table 1 (continued). Effect of parasitic infections on the immune response to vaccines.

\begin{tabular}{|c|c|c|c|c|c|c|c|}
\hline \multicolumn{8}{|c|}{ Others vaccines } \\
\hline \multirow{9}{*}{ Malaria } & \multirow{3}{*}{$\begin{array}{l}\text { Simondon et al., } \\
1999 \text { [58] Senegal } \\
\text { Pertussis toxin }\end{array}$} & \multirow{3}{*}{$\begin{array}{c}\text { Children } \\
\text { (1-2 months old) }\end{array}$} & \multirow{3}{*}{$\begin{array}{l}\text { Exposed to } P \text {. } \\
\text { falciparum }\end{array}$} & Study groups & $\begin{array}{l}\text { Antibody titres } \\
\text { (GMT) }\end{array}$ & \multirow{3}{*}{$<0.05$} & \multirow{3}{*}{$\begin{array}{l}\text { The antibody } \\
\text { response to pertussis } \\
\text { toxin was lower in } \\
\text { infants infected with } \\
\text { malaria than in a } \\
\text { group of healthy } \\
\text { infants. }\end{array}$} \\
\hline & & & & $\begin{array}{l}\text { Infected } \\
(\mathrm{n}=66)\end{array}$ & $81.1(72.4-91.2)$ & & \\
\hline & & & & $\begin{array}{l}\text { Uninfected } \\
(\mathrm{n}=115)\end{array}$ & $97.3(87.1-107.1)$ & & \\
\hline & \multirow[b]{2}{*}{$\begin{array}{l}\text { Malhotra et al., } \\
2015 \text { [40] Kenya } \\
\text { Hepatitis B }\end{array}$} & \multirow[b]{2}{*}{$\begin{array}{c}\text { Mothers/children } \\
(>14 \text { years old } / 6-36 \\
\text { months old })\end{array}$} & \multirow[b]{2}{*}{$\begin{array}{l}\text { Exposed in } \\
\text { utero to } P \text {. } \\
\text { falciparum }\end{array}$} & $\begin{array}{l}\text { Sensitized } \\
(\mathrm{n}=188)\end{array}$ & \multirow[b]{2}{*}{ NI } & \multirow[b]{2}{*}{ NS } & \multirow{2}{*}{$\begin{array}{l}\text { The levels of IgG } \\
\text { specific against } \\
\text { Hepatitis B were not } \\
\text { affected in children } \\
\text { sensitized by } P \text {. } \\
\text { falciparum }\end{array}$} \\
\hline & & & & $\begin{array}{l}\text { Unexposed } \\
(\mathrm{n}=179)\end{array}$ & & & \\
\hline & \multirow{4}{*}{$\begin{array}{c}\text { Brown et al., } 2014 \\
\text { [59] Tanzania } \\
\text { human } \\
\text { papillomavirus- } \\
\text { 16/18 AS04- } \\
\text { adjuvanted }\end{array}$} & \multirow{4}{*}{$\begin{array}{c}\text { Women } \\
\text { (10-25 years old) }\end{array}$} & \multirow{4}{*}{$\begin{array}{l}\text { Infection by } S \text {. } \\
\text { haematobium; } \\
\text { S. mansoni; } \\
\text { Strongyloides } \\
\text { stercolaris; } \\
\text { Ascaris } \\
\text { lumbricoides; } \\
\text { Trichuris } \\
\text { trichiura; } \\
\text { Taenia spp. }\end{array}$} & Study groups & $\begin{array}{c}\text { Antibody titres } \\
\mathrm{EU} / \mathrm{mL}\end{array}$ & \multirow[b]{2}{*}{$\begin{array}{l}\mathbf{0 . 0 5} \\
0.59\end{array}$} & \multirow{4}{*}{$\begin{array}{l}\text { High HPV } \\
\text { immunogenicity } \\
\text { regardless of the } \\
\text { presence of malaria } \\
\text { and helminth } \\
\text { infections among } \\
\text { young girls and } \\
\text { women in Tanzania. } \\
\text { There was some } \\
\text { evidence of enhanced } \\
\text { antibody titres to } \\
\text { HPV vaccine } \\
\text { genotypes in } \\
\text { participants with } \\
\text { malaria parasitaemia. }\end{array}$} \\
\hline & & & & $\begin{array}{l}\text { Malaria } \\
(\mathrm{n}=20)\end{array}$ & $\begin{array}{c}\text { HPV16 4335(2890- } \\
6502) \text { HPV18 } \\
1109(764-1609)\end{array}$ & & \\
\hline & & & & $\begin{array}{l}\text { Helminth } \\
(\mathrm{n}=59)\end{array}$ & $\begin{array}{c}\text { HPV16 } 2843 \text { (2171- } \\
3723) \text { HPV18 } 1038 \\
(802-1344)\end{array}$ & $\begin{array}{l}0.64 \\
0.71\end{array}$ & \\
\hline & & & & $\begin{array}{l}\text { Uninfected } \\
(\mathrm{n}=129)\end{array}$ & $\begin{array}{c}\text { HPV16 } 2613 \text { (2124- } \\
\text { 3215) HPV18 } 970 \\
\text { (781-1205) }\end{array}$ & & \\
\hline \multirow[b]{2}{*}{ Schistosomosis } & \multirow[b]{2}{*}{$\begin{array}{l}\text { Malhotra et al., } \\
2015 \text { [40] Kenya } \\
\text { Hepatitis B }\end{array}$} & \multirow[b]{2}{*}{$\begin{array}{c}\text { Mothers/children } \\
\text { (> } 14 \text { years old/ 6-36 } \\
\text { months old) }\end{array}$} & \multirow[b]{2}{*}{$\begin{array}{l}\text { Exposed in } \\
\text { utero to } S \text {. } \\
\text { haematobium }\end{array}$} & $\begin{array}{l}\text { Sensitized } \\
(\mathrm{n}=238)\end{array}$ & & & \multirow{2}{*}{$\begin{array}{l}\text { Sensitization by S. } \\
\text { haematobium was not } \\
\text { associated with } \\
\text { significantly lower } \\
\text { Hepatitis B -specific } \\
\text { IgG. }\end{array}$} \\
\hline & & & & $\begin{array}{l}\text { Unexposed } \\
(\mathrm{n}=90)\end{array}$ & NI & NS & \\
\hline \multirow[b]{2}{*}{ Filarioidosis } & \multirow{2}{*}{$\begin{array}{l}\text { Malhotra et al., } \\
2015 \text { [40] Kenya } \\
\text { Hepatitis B }\end{array}$} & \multirow{2}{*}{$\begin{array}{c}\text { Mothers/children } \\
\text { (>14 years old/ 6-36 } \\
\text { months old })\end{array}$} & \multirow{2}{*}{$\begin{array}{l}\text { Exposed in } \\
\text { utero to } \\
\text { B. malayi or } \\
W . \text { bancrofti }\end{array}$} & $\begin{array}{l}\text { Sensitized } \\
(\mathrm{n}=167)\end{array}$ & & & \multirow{2}{*}{$\begin{array}{c}\text { Sensitization by } \\
\text { filarioidosis was not } \\
\text { associated with } \\
\text { significantly lower } \\
\text { Hepatitis B -specific } \\
\text { IgG. }\end{array}$} \\
\hline & & & & $\begin{array}{l}\text { Unexposed } \\
(\mathrm{n}=110)\end{array}$ & NI & NS & \\
\hline \multirow{6}{*}{ Helminthosiss } & \multirow{3}{*}{$\begin{array}{c}\text { Brückner et al., } \\
2015 \text { [60] Gabon } \\
\text { Seasonal } \\
\text { influenza }\end{array}$} & \multirow{3}{*}{$\begin{array}{c}\text { Children } \\
\text { (6-10 years old) }\end{array}$} & \multirow{3}{*}{$\begin{array}{l}\text { Infection by } \\
\text { A. } \\
\text { lumbricoides; } \\
\text { Ancylostoma } \\
\text { duodenale; } \\
\text { Fasciola } \\
\text { hepatica; } T \text {. } \\
\text { trichiura }\end{array}$} & Study groups & Antibody HI titres & \multirow{3}{*}{ NS } & \multirow{3}{*}{$\begin{array}{l}\text { There was no } \\
\text { significant difference } \\
\text { in the HI titers against } \\
\text { the influenza vaccine } \\
\text { between the two } \\
\text { study groups. }\end{array}$} \\
\hline & & & & $\begin{array}{c}\text { Antihelminthi } \\
\mathrm{c} \\
(\mathrm{n}=44)\end{array}$ & $\begin{array}{c}\text { AH1N1 320(35- } \\
960) \text { AH3N2 } \\
320(280-640) \\
\text { B/Brisbone } 320 \\
(280-640)\end{array}$ & & \\
\hline & & & & $\begin{array}{l}\text { Placebo } \\
(\mathrm{n}=38)\end{array}$ & $\begin{array}{c}\text { AH1N1 } 320(20- \\
480) \text { AH3N2 } 320 \\
(240-600) \\
\text { B/Brisbone } 160 \\
(80-800)\end{array}$ & & \\
\hline & \multirow{3}{*}{$\begin{array}{c}\text { Cooper } \text { et al., } \\
2001 \text { [34] Ecuador } \\
\text { Live oral cholera } \\
\text { vaccine CVD } \\
\mathbf{1 0 3 - H g R}\end{array}$} & & & Study groups & $\begin{array}{c}\text { Cytokines levels } \\
\mathrm{pg} / \mathrm{mL}\end{array}$ & & $\begin{array}{l}\text { A. lumbricoides- } \\
\text { infected subjects who }\end{array}$ \\
\hline & & Subiects & & $\begin{array}{l}\text { Anthelminthic } \\
\quad(\mathrm{n}=15)\end{array}$ & $\begin{array}{l}\text { IL2: } 21,8(0-74) \\
\text { INF } \gamma: 7,7(0-209,7)\end{array}$ & $\begin{array}{l}\text { IL2 } \\
0.03\end{array}$ & \\
\hline & & & lumbricoldes & $\begin{array}{l}\text { Placebo } \\
(\mathrm{n}=13)\end{array}$ & $\begin{array}{l}\text { IL2: } 0(0-252,9) \\
\text { INFy: } 7,9(0-298,2)\end{array}$ & $\begin{array}{l}\text { INF } \gamma \\
\text { NS }\end{array}$ & $\begin{array}{c}\text { vaccination } \\
\text { demonstrated a } \\
\text { depressed IL-2 } \\
\text { response. }\end{array}$ \\
\hline
\end{tabular}

CI: Confidence interval; NI: No information; NS: The probability value is not reported but is said to be non-significant; IU/mL: International Units per milliliter; pg/mL: picograms per milliliter; mm: millimeter; Log2: logarithm base 2; $\mu \mathrm{g} / \mathrm{mL}$ : micrograms per milliliter; GMT: geometric mean titres; EU/mL: equivalent units per milliliter; HI: hemagglutinin-inhibition; $p$ values were considered significant considering a 95\% confidence interval. 
Table 2. Effect of chemoprophylaxis for malaria on the immune response to vaccines.

\begin{tabular}{|c|c|c|c|c|c|c|}
\hline Reference & $\begin{array}{c}\text { Population } \\
\text { age range }\end{array}$ & $\begin{array}{l}\text { Exposition } \\
\text { factor }\end{array}$ & \multicolumn{2}{|c|}{ Average (CI) } & $\mathbf{p}$ & Authors' conclusion \\
\hline \multicolumn{7}{|c|}{ Tetanus toxoid } \\
\hline $\begin{array}{c}\text { McGregor et } \\
\text { al.,1962 [61] } \\
\text { Gambia }\end{array}$ & $\begin{array}{l}\text { Subjects } \\
(5-70 \text { years } \\
\text { old })\end{array}$ & $\begin{array}{l}\text { Chloroquine } \\
\text { (CQ) } \\
\text { Pyrimethamine } \\
\text { (PT) }\end{array}$ & $\begin{array}{l}\text { Study groups } \\
\text { CQ }(\mathrm{n}=16) \\
\text { PT }(\mathrm{n}=14) \\
\text { No-chemoproph. } \\
\quad(\mathrm{n}=36)\end{array}$ & $\begin{array}{c}\text { Antibody levels } \\
0.19 \mathrm{IU} / \mathrm{mL} \\
0.18 \mathrm{IU} / \mathrm{mL}\end{array}$ & NS & \multirow{2}{*}{$\begin{array}{l}\text { There were significantly more } \\
\text { patients who did not respond to the } \\
\text { vaccine in the group without } \\
\text { chemoprophylaxis. However, no } \\
\text { differences were observed in } \\
\text { antibody levels between the } \\
\text { groups. } \\
\text { No difference in antibody levels } \\
\text { against the tetanus toxoid vaccine } \\
\text { was observed in the groups with or } \\
\text { without CQ administration. }\end{array}$} \\
\hline $\begin{array}{l}\text { Greenwood et al., } \\
1981 \text { [62] Nigeria }\end{array}$ & $\begin{array}{l}\text { Children } \\
\text { (3-17 months } \\
\text { old) }\end{array}$ & Chloroquine & $\begin{array}{l}\text { Study groups } \\
\text { CQ }(\mathrm{n}=93) \\
\text { no-CQ }(\mathrm{n}=91)\end{array}$ & $\begin{array}{c}\text { Antibody levels } \\
5.7 \log 2(3.1-8.6 \log 2) \\
5.9 \log 2(5.5-6.3 \log 2)\end{array}$ & NS & \\
\hline $\begin{array}{l}\text { Monjour et al., } \\
1982 \text { [63] Burkina } \\
\text { Faso }\end{array}$ & $\begin{array}{l}\text { Children } \\
\text { (11 months-3 } \\
\text { years old) }\end{array}$ & $\begin{array}{l}\text { Amodiaquine } \\
\text { (AQ) }\end{array}$ & $\begin{array}{c}\text { Study groups } \\
\text { AQ }(\mathrm{n}=159) \\
\text { no-AQ }(\mathrm{n}=126)\end{array}$ & $\begin{array}{c}\text { Antibody levels } \\
\text { NI }\end{array}$ & $>0.05$ & $\begin{array}{l}\text { There were no differences in the } \\
\text { levels of protection between the } \\
\text { groups. }\end{array}$ \\
\hline $\begin{array}{l}\text { Gilles et al., } 1983 \\
\text { [64] Nigeria }\end{array}$ & $\begin{array}{c}\text { Children } \\
\text { (1-5 years old })\end{array}$ & $\begin{array}{l}\text { CQ } \\
\text { Asymtomatic } \\
\text { malaria }\end{array}$ & $\begin{array}{c}\text { Study groups } \\
\text { CQ }(\mathrm{n}=123) \\
\text { no-CQ }(\mathrm{n}=119)\end{array}$ & $\begin{array}{c}\text { Antibody levels } \\
1.31 \mathrm{IU} / \mathrm{mL}(1.06-1.56) \\
1.25 \mathrm{IU} / \mathrm{mL}(0.94-1.56)\end{array}$ & NS & $\begin{array}{l}\text { Malaria chemoprophylaxis was not } \\
\text { necessary in the first year of life to } \\
\text { achieve protection of infants } \\
\text { against tetanus. }\end{array}$ \\
\hline $\begin{array}{c}\text { Brabin et al., } 1984 \\
\text { [65] Kenya }\end{array}$ & $\begin{array}{l}\text { Pregnant } \\
\text { women }\end{array}$ & CQ & $\begin{array}{l}\text { CQ: }(\mathrm{n}=107) \\
\text { no-CQ }(\mathrm{n}=73)\end{array}$ & NI & NS & $\begin{array}{l}\text { No difference was found in } \operatorname{IgG} \\
\text { titers against tetanus toxoid } \\
\text { vaccine. All women responded } \\
\text { appropriately to the vaccine. }\end{array}$ \\
\hline $\begin{array}{l}\text { Schellenberg et al., } \\
2001 \text { [66] Tanzania }\end{array}$ & $\begin{array}{c}\text { Children } \\
\text { (2 months old) }\end{array}$ & $\begin{array}{l}\text { Sulfadoxine- } \\
\text { Pyrimethamine } \\
\text { (SP) }\end{array}$ & $\begin{array}{c}\mathrm{SP}(\mathrm{n}=351) \\
\text { No-SP }(\mathrm{n}=351)\end{array}$ & NI & NS & $\begin{array}{l}\text { No differences in the rate of } \\
\text { seroconversion for tetanus. }\end{array}$ \\
\hline $\begin{array}{l}\text { Massaga et al., } \\
2003 \text { [67] Tanzania }\end{array}$ & $\begin{array}{c}\text { Children } \\
\text { (12-16 weeks) }\end{array}$ & AQ & $\begin{array}{l}\text { Study group } \\
\text { AQ }(\mathrm{n}=77) \\
\text { Placebo }(63)\end{array}$ & $\begin{array}{c}\text { Antibody levels } \\
12.7 \mathrm{IU} / \mathrm{mL}(7.6-18.7) \\
10.4 \mathrm{IU} / \mathrm{mL}(6.1-13.7)\end{array}$ & 0.28 & $\begin{array}{l}\text { The administration of AQ together } \\
\text { with the vaccination against tetanus } \\
\text { toxoid did not change the antibody } \\
\text { levels generated by the vaccination. }\end{array}$ \\
\hline $\begin{array}{l}\text { Rosen et al., } 2005 \\
\text { [68] Burkina Faso }\end{array}$ & $\begin{array}{l}\text { Children } \\
\text { (4 months-6 } \\
\text { years old) }\end{array}$ & AQ & $\begin{array}{c}\text { Study group } \\
\text { AQ }(\mathrm{n}=134) \\
\text { no-AQ }(\mathrm{n}=138)\end{array}$ & $\begin{array}{l}\text { Seroconversion } \\
104 / 134(77 \%) \\
126 / 138(91 \%)\end{array}$ & 0.08 & $\begin{array}{l}\text { Chemoprophylaxis of malaria } \\
\text { before vaccination in endemic } \\
\text { areas of malaria does not improve } \\
\text { or deteriorate the immunogenicity } \\
\text { of tetanus toxoid vaccine. }\end{array}$ \\
\hline & & & & & & \\
\hline Reference & $\begin{array}{l}\text { Population } \\
\text { age range }\end{array}$ & $\begin{array}{l}\text { Exposition } \\
\text { factor }\end{array}$ & & ge (CI) & $\mathbf{p}$ & Author's conclusion \\
\hline $\begin{array}{l}\text { Greenwood et al., } \\
1981 \text { [62] Nigeria }\end{array}$ & $\begin{array}{l}\text { Children } \\
\text { (3-17 month } \\
\text { old })\end{array}$ & CQ & $\begin{array}{c}\text { Study group } \\
\text { CQ }(\mathrm{n}=93) \\
\text { no-CQ }(\mathrm{n}=91)\end{array}$ & $\begin{array}{c}\text { Antibody levels } \\
3.5 \log 2(3.1-3.9 \log 2) \\
2.9 \log 2(2.6-3.2 \log 2)\end{array}$ & NS & $\begin{array}{c}\text { No difference in antibody levels } \\
\text { against measles was observed in } \\
\text { the groups with or without CQ } \\
\text { administration. }\end{array}$ \\
\hline $\begin{array}{l}\text { Gilles et al., } 1983 \\
\text { [64] Nigeria }\end{array}$ & $\begin{array}{c}\text { Children } \\
\text { (1-5 years old })\end{array}$ & $\begin{array}{c}\text { CQ } \\
\text { Asymptomatic } \\
\text { malaria }\end{array}$ & $\begin{array}{c}\text { Study group } \\
\text { CQ }(\mathrm{n}=121) \\
\text { no-CP }(\mathrm{n}=116)\end{array}$ & $\begin{array}{c}\text { Antibody levels } \\
5.15 \mathrm{IU} / \mathrm{mL}(2.34-7.96) \\
5.57 \mathrm{IU} / \mathrm{mL}(3.21-7.93)\end{array}$ & NS & $\begin{array}{l}\text { Malaria chemoprophylaxis is not } \\
\text { necessary in the first year of life to } \\
\text { achieve the infant protection } \\
\text { against measles. }\end{array}$ \\
\hline $\begin{array}{c}\text { Cénac et al., } 1988 \\
\text { [69] Niger }\end{array}$ & $\begin{array}{l}\text { Children } \\
\text { (9- } 48 \text { months } \\
\text { old) }\end{array}$ & CQ & $\begin{array}{c}\text { Study group } \\
\text { CQ }(\mathrm{n}=289) \\
\text { no-CQ }(\mathrm{n}=291)\end{array}$ & $\begin{array}{l}\text { Seroconversion } \\
218 / 289(76 \%) \\
238 / 291(82 \&)\end{array}$ & NS & $\begin{array}{l}\text { The seroconversion was not } \\
\text { significantly different between the } \\
\text { groups. }\end{array}$ \\
\hline $\begin{array}{l}\text { Rosen et al., } 2005 \\
\text { [68] Burkina Faso }\end{array}$ & $\begin{array}{l}\text { Children } \\
\text { (4 months-6 } \\
\text { years old) }\end{array}$ & AQ & $\begin{array}{c}\text { Study group } \\
\text { AQ }(\mathrm{n}=137) \\
\text { no-AQ }(\mathrm{n}=187)\end{array}$ & $\begin{array}{l}\text { Seroconversion } \\
127 / 137(93 \%) \\
180 / 187(96 \%)\end{array}$ & 0.16 & $\begin{array}{l}\text { Chemoprophylaxis of malaria } \\
\text { before vaccination in endemic } \\
\text { areas of malaria does not improve } \\
\text { or deteriorate the immunogenicity } \\
\text { of measles vaccine. }\end{array}$ \\
\hline
\end{tabular}


Table 2. Effect of chemoprophylaxis for malaria on the immune response to vaccines.

\begin{tabular}{|c|c|c|c|c|c|c|}
\hline Reference & $\begin{array}{l}\text { Population } \\
\text { age range }\end{array}$ & $\begin{array}{l}\text { Exposition } \\
\text { factor }\end{array}$ & \multicolumn{2}{|c|}{ Average (CI) } & $\mathbf{p}$ & Authors' conclusion \\
\hline \multicolumn{7}{|c|}{ Others } \\
\hline \multirow{5}{*}{$\begin{array}{c}\text { Gilles et al., } 1983 \\
\text { [64] Nigeria } \\
\text { Polio } \mathbf{1 , 2} \text { and } \mathbf{3}\end{array}$} & \multirow{4}{*}{$\begin{array}{c}\text { Children } \\
(1-5 \text { years old })\end{array}$} & \multirow{4}{*}{$\begin{array}{c}\text { CQ } \\
\text { Asymptomatic } \\
\text { malaria }\end{array}$} & Study group & Antibody levels GMT & & \multirow{4}{*}{$\begin{array}{l}\text { Malaria chemoprophylaxis is not } \\
\text { necessary in the first year of life to } \\
\text { achieve the infant protection } \\
\text { against poliovirus vaccine. }\end{array}$} \\
\hline & & & CQ $(n=29)$ & $\begin{array}{l}\text { Polio 1: } 379( \pm 609) \\
\text { Polio 2: } 134( \pm 217) \\
\text { Polio 3: } 210( \pm 363) \\
\text { Polio 1. } 1344( \pm 2320)\end{array}$ & NS & \\
\hline & & & & Polio 1: $1344( \pm 2320)$ & & \\
\hline & & & no-CP $(\mathrm{n}=19)$ & $\begin{array}{l}\text { Polio 2: } 145( \pm 193) \\
\text { Polio 3: } 190( \pm 311)\end{array}$ & & \\
\hline & \multirow{3}{*}{$\begin{array}{l}\text { School } \\
\text { children } \\
(4-16 \text { years } \\
\text { old })\end{array}$} & \multirow{3}{*}{$\begin{array}{c}\text { Atovaquone/ } \\
\text { Proguanil (AP) }\end{array}$} & Study group & Antibody levels GMT & $\operatorname{IgG}$ & \multirow{3}{*}{$\begin{array}{l}\text { The two treatment groups did not } \\
\text { differ significantly with respect to } \\
\text { changes in antibody titers after } \\
\text { vaccination. }\end{array}$} \\
\hline \multirow{2}{*}{$\begin{array}{c}\text { Faucher et al., } 2002 \\
\text { [70] Gabon } \\
\text { Live Oral } \\
\text { Typhoid and } \\
\text { Cholera vaccines }\end{array}$} & & & $\mathrm{AP}(\mathrm{n}=165)$ & $\begin{array}{l}\text { IgG S. typhi: } 2.99( \pm 1.21) \\
\text { IgA S. typhi:0.97( } \pm 1.13) \\
\text { IgG cholera }: 5.4( \pm 1.0)\end{array}$ & $\begin{array}{l}\text { S. typhi } \\
0.958 \\
\text { IgA } S .\end{array}$ & \\
\hline & & & Placebo $(n=165)$ & $\begin{array}{l}\text { IgG S. typhi: } 2.99( \pm 1.27) \\
\text { IgA S. typhi: } 0.88( \pm 1.12) \\
\text { IgG cholera }: 5.3( \pm 1.0)\end{array}$ & $\begin{array}{l}\text { typhi: } \\
0.072 \text { IgG } \\
\text { cholera } \\
0.637\end{array}$ & \\
\hline \multirow{2}{*}{$\begin{array}{l}\text { Rosen et al., } 2005 \\
\text { [68] Burkina Faso } \\
\text { Diphtheria toxoid }\end{array}$} & \multirow{2}{*}{$\begin{array}{l}\text { Children } \\
(4 \text { months-6 } \\
\text { years old) }\end{array}$} & \multirow[t]{2}{*}{ AQ } & $\begin{array}{l}\text { Study group } \\
\text { AQ }(n=147)\end{array}$ & $\begin{array}{l}\text { Seroconversion } \\
108 / 147(73 \%)\end{array}$ & \multirow[t]{2}{*}{0.26} & \multirow{2}{*}{$\begin{array}{l}\text { Chemoprophylaxis of malaria } \\
\text { before vaccination in endemic } \\
\text { areas of malaria did not improve or } \\
\text { deteriorate the immunogenicity of } \\
\text { diphtheria toxoid vaccine. }\end{array}$} \\
\hline & & & no-AQ $(\mathrm{n}=135)$ & $116 / 135(86 \%)$ & & \\
\hline
\end{tabular}

CI: Confidence interval; NI: no information; NS: The probability value is not reported but is said to be non-significant; CQ: Chloroquine; AQ: Amodiaquine; PT: Pyrimethamine; SP: Sulfadoxine/pyrimethamine; AP: Atovaquone/proguanil; IU/mL: International Units per milliliter; GMT: geometric mean titres; $p$ values were considered significant considering a $95 \%$ confidence interval.

In addition, for antigens such as the Bacillus Calmette-Guérin (BCG) vaccine and Mycobacterium tuberculosis, the cellular immune response is important; $\mathrm{CD}^{+} \mathrm{T}$ cells exert their effect by producing gamma interferon (IFN- $\gamma$ ), primarily, after stimulation with mycobacterial antigens [27]. Parasitic infections can limit the amplification of the IFN- $\gamma$ response necessary for the immune response against this pathogen.

On the other hand, it is important to emphasize that polyparasitism affects a large number of people residing in tropical and subtropical regions. Simultaneous parasitic infections enhance and promote the persistence of the regulatory immune profile in infected subjects, which exacerbates the problem. All this has been revealed by studies that associate the modulation caused by parasites with the increased virulence of lethal pathogens such as the human immunodeficiency virus (HIV) [28,29] and Mycobacterium tuberculosis [30-31].

The Expanded Immunization Program (EIP) aims to control, eliminate, and eradicate several immunopreventable diseases. The EIP is the result of joint actions by nations to achieve the technical capacity and political support necessary to improve universality in vaccination coverage [32]. Since the implementation of this program, a reduction in morbidity and mortality of those diseases has been clearly observed. In addition to high vaccine coverage as a primary objective, the effectiveness of vaccines must also be ensured. This effectiveness is understood as the conservation of the quantity and quality of the immune response obtained in a parasitized population compared to a nonparasitized population (control).

The objective of this review was to compile, summarize and analyze information about immunomodulation by parasitic infections and its effects on the immune response to vaccines. We also identified the parasites most associated with immunomodulation of vaccine responses and those vaccines most affected.

\section{Methodology}

A search was carried out in the PubMed, Scopus, and Web of science (WOS) databases. Several search strategies were employed using combinations of MeSH [Majr] terms such as "tetanus toxoid", "BCG vaccine", "Bacterial vaccines", "Malaria", "Helminths", among others; and not MeSH terms such as "parasitic infections", "vaccination efficacy", "impairment vaccination efficacy" and "parasites". The central subject of the search was the influence of parasitic infections on the human immune response to bacterial and viral vaccines; however, studies that evaluated the effect of chemoprophylaxis for malaria on the response to bacterial and viral vaccines were also included. First, the papers were selected based on the title, and then based on the abstract. The inclusion criteria were: 1) Original studies or systematic reviews about the effect of parasitic infections or chemoprophylaxis for malaria on the immune response to vaccines. 2) Studies carried out in humans. There were no date or language 
restrictions. The search deadline was July 10, 2018. A total of 19 papers that evaluated the effect of parasitic infections on the immune response against different vaccines, and 10 papers that evaluated the effect of chemoprophylaxis for malaria on the response to vaccines were included.

\section{Results}

Effect of parasitic infections on the immune response to vaccination

The relevant parasitic infections were: filarioidosis, schistosomosis, malaria and geohelminthosis. In these studies, the vaccines evaluated were tetanus toxoid, diphtheria toxoid, BCG, bacterial polysaccharides vaccines, hepatitis $\mathrm{B}$, pertusis toxin, human papillomavirus, seasonal influenza and live oral cholera (Table 1). Chemoprophylaxis for malaria with chloroquine, amodiaquina, sulfadoxine/pyrimethamine and atovaquone/proguanil were evaluated; in these studies, the vaccines evaluated were tetanus toxoid, measles, poliovirus, live oral cholera and diphtheria toxoid (Table 2).

\section{Discussion}

The influence of parasitic infections on the efficacy of bacterial and viral vaccines has been scarcely studied and there are conflicting results. Most of the studies found in this review, with the exception of Cooper's work in 1999 and 2001 [33,34], were carried out in Africa and some countries in Asia.

This review shows that the immune response generated by bacterial polysaccharide vaccines and the BCG vaccine is affected by the presence of malaria, filarioidosis and schistosomosis. On the other hand, the effect of parasitic infections on the response to tetanus toxoid vaccine shows discordant results. Only two over six studies that evaluated the effect of malaria on the immune response against tetanus toxoid showed a decrease in IgG levels against the vaccine $[35,36]$ (Table 1). However, it is important to note that each study includes different groups and different clinical presentation of malaria. In a recent study carried out in pregnant women, submicroscopic infection by Plasmodium was associated with a decrease in the levels of IgG against tetanus toxoid [37]. In the same way, of four studies that evaluated the effect of filarioidosis in the immune response against tetanus toxoid, two showed a decrease in IgG levels against tetanus toxoid vaccine $[38,39]$, while two did not show differences between the groups $[33,40]$ (Table 1). In general, those studies that reported changes in antibody levels after tetanus toxoid vaccination in the presence of parasitic infections had smaller sample sizes compared with the studies without differences between the groups, which included more than 100 subjects. In addition, the levels of antibodies generated by the diphtheria toxoid vaccine were not affected by the presence of parasitic infection.

It seems clear that vaccines such as tetanus toxoid and diphtheria toxoid, despite parasitic infections, continue to fulfill their protective function, as can be deduced from the drastic decline in morbidity observed after their use. However, a vaccine such as BCG is only partially effective because it provides some protection against severe forms of pediatric tuberculosis but is not completely protective against pulmonary disease in infants and is unreliable against adult pulmonary tuberculosis. In spite of nearly a century of use, BCG remains controversial, with known variations in vaccine efficacy across the world [41]. Nonetheless, it should be emphasized that parasitic infections can lead to lower antibody and INF $\gamma$ levels, which represent a decrease in the quality of the humoral and cellular acquired immune responses. Moreover, this review shows that in all cases, the parasitic infections affected the immune response generated by bacterial polysaccharide vaccines. In general, the nature of polysaccharide antigens poses a challenge to the generation of longterm immunological memory [42]. Encapsulated bacteria are the main causes of bacteremia, pneumonia, and meningitis in childhood globally [43]. For this reason, the burden of parasitic infections in vaccinees should be considered with respect to the quality of the immune response generated by polysaccharide vaccines.

Parasitic infections can be chronic, and the persistence of the antigenic stimulus changes the expression of immune mediators and promotes constant immune regulation, including increases in regulatory $\mathrm{T}$ cell populations [44]. These alterations of the immune system could compromise the response to routine vaccination. Chronic infections are associated with exhausted T cells with less robust effector functions and with alterations in the differentiation of memory $\mathrm{T}$ cells [45]. The exhausted $\mathrm{T}$ cells manifest characteristic features including sustained up-regulation and coexpression of multiple inhibitory receptors and failure to produce antigen-independent memory $\mathrm{T}$ cells [46]. For this reason, the parasitic infections may induce impaired efficacy in the immunological processes in general, and until now, studies evaluating the immune response to vaccination are insufficient and with heterogeneous results. 
Malaria and geohelminthosis are the parasitic infections most widely distributed in the world. It is important to explore if the general modulation of the immune system caused by these parasitic infections affects the immune response against different pathogens $[29,47,48]$. Parasitic co-infections can occur frequently, and more studies are needed to explore the effect of multiple parasitic infections on vaccine response and in the immune response against different pathogens.

In conclusion, individuals living in the tropical and subtropical areas of the world are most susceptible to alterations in the immune response, not only because of the large number of parasites they face on a daily basis, but also because these host-parasite interactions affect: 1) the generation of tolerance to parasitic infections; 2) the response efficacy against pathogens such as bacteria and viruses; 3) the ability to acquire protective immunity against vaccines and against pathogens. This situation would pose a serious challenge for the EIP and for other vaccines not included in the program. The available data, reviewed here, are insufficient but suggest that alteration of acquired protective immunity from vaccines does occur. From the point of view of public health, it is necessary to evaluate this subject in terms of the level of parasite prevalence in different populations and according to polyparasitism. This highlights the need for increasing studies on this subject, especially in the American continent, where millions of people are affected by multiple parasitic infections.

\section{Acknowledgements}

This work was funded by COLCIENCIAS (contracts 111574454975), and Universidad de Antioquia (Estrategia de Sostenibilidad 2016-2017). The authors thank Dr. Stephanie Yanow for their comments on the manuscript.

\section{References}

1. Fariñas GF (2014) Nutrition, infection and immunity: clinical implications, preventive and therapeutic measures. In Trescastro-López EM. Hunger editors, Misery and Disease in Latin America and the Caribbean: the Role of Nutrition in Neglected Tropical Diseases (NTDs) in Nicaragua. Valencia: University of Alicante, Nunut Nutrididáctica. . 198-231. [Book in Spanish]

2. Martínez R (2005) Hunger and inequality in the Andean countries. Malnutrition and food vulnerability in Bolivia, Colombia, Ecuador and Peru. Social Policies Series N ${ }^{\circ} 112$. Santiago de Chile: United Nations 95p.. [Book in Spanish]

3. Breilh J (2003) Critical epidemiology. Emancipatory and intercultural science. Buenos Aires:Lugar Editorial 320 p. [Book in Spanish]

4. Almeida N (2000) Timid science: trials of deconstruction of epidemiology. Buenos Aires: Lugar Editorial 327 p. [Book in Spanish]
5. Farmer $P$ (2000). Social inequalities and emerging infectious diseases. Population papers 6: 181-201.

6. Valdés García LE (2000). Poverty and emerging and reemerging diseases. Medisan 4: 39-50. [Article in Spanish]

7. Pan American Health Organization (2017) Health in the Americas, 2017 Edition. Summary: Regional Outlook and Country Profiles. Washington, D.C. Available: https://www.paho.org/salud-en-las-americas-2017/wpcontent/uploads/2017/09/Print-Version-English.pdf. Accessed 7 September 2018.

8. Malhotra I, Dent A, Mungai P, Wamachi A, Ouma JH, Narum DL, Muchiri E, Tisch DJ, King CL (2009) Can prenatal malaria exposure produce an immune tolerant phenotype?: A prospective birth cohort study in Kenya. PLoS Med 6: e1000116.

9. Johnston CJ, Smyth DJ, Dresser DW, Maizels RM (2016) TGF- $\beta$ in tolerance, development and regulation of immunity Cell. Immunol 299: 14-22

10. Johnston CJ, McSorley HJ, Anderton SM, Wigmore SJ, Maizels RM (2014) Helminths and immunological tolerance. Transplantation 97: 127-132

11. Mpairwe H, Tweyongyere R, Elliott A (2014). Pregnancy and helminth infections. Parasite Immunol 36: 328-337

12. MacGillivray DM, Kollmann TR (2014) The role of environmental factors in modulating immune responses in early life. Front Immunol 5: 434.

13. World Heath Organization (2017) Global vector control response 2017-2030. Available: http://apps.who.int/iris/bitstream/handle/10665/259205/97892 41512978eng.pdf;jsessionid=B82CD8BEE847826ED91B6BC8EF4BE 076 ? sequence $=1$. Accessed 11 November 2017.

14. Blackwell (2003) Session 9: Chronic infection and regulation in the immune system. Immunology 110 Suppl 1:26-33.

15. McSorley HJ, Maizels RM (2012) Helminth infections and host immune regulation. Clin Microbiol Rev 25: 585-608

16. Santos P, Lorena VM, Fernandes ÉS, Sales IR, Nascimento WR, Gomes YM, Albuquerque MC, Costa VM, Souza VM (2016) Gestation and breastfeeding in schistosomotic mothers differently modulate the immune response of adult offspring to postnatal Schistosoma mansoni infection. Mem Inst Oswaldo Cruz 111: 83-92

17. Metenou S, Coulibaly YI, Sturdevant D, Dolo H, Diallo AA, Soumaoro L, Coulibaly ME, Kanakabandi K, Porcella SF, Klion AD, Nutman TB (2014) Highly heterogeneous, activated, and short-lived regulatory $\mathrm{T}$ cells during chronic filarial infection. Eur J Immunol 44: 2036-2047

18. Walther M, Jeffries D, Finney OC, Njie M, Ebonyi A, Deininger S, Lawrence E, Ngwa-Amambua A, Jayasooriya S, Cheeseman IH, Gomez-Escobar N, Okebe J, Conway DJ, Riley EM (2009) Distinct roles for FOXP3 and FOXP3 CD4 T cells in regulating cellular immunity to uncomplicated and severe Plasmodium falciparum malaria. PLoS Pathog 5: e1000364.

19. Kho S, Marfurt J, Handayuni I, Pava Z, Noviyanti R, Kusuma A, Piera KA, Burdam FH, Kenangalem E, Lampah DA, Engwerda CR, Poespoprodjo JR, Price RN, Anstey NM, Minigo G, Woodberry T (2016) Characterization of blood dendritic and regulatory $\mathrm{T}$ cells in asymptomatic adults with sub-microscopic Plasmodium falciparum or Plasmodium vivax infection. Malar J 15: 328.

20. MacDonald AS, Araujo MI, Pearce EJ (2012) Immunology of parasitic helminth infections. Infect Immun 70: 427-433

21. van Riet E, Hartgers FC, Yazdanbakhsh M (2007) Chronic helminth infections induce immunomodulation: consequences and mechanisms. Immunobiology 212: 475-490. 
22. Labeaud AD, Malhotra I, King MJ, King CL, King CH (2009) Do antenatal parasite infections devalue childhood vaccination? PLoS Negl Trop Dis 3: e442.

23. Groux H, O'Garra A, Bigler M, Rouleau M, Antonenko S, de Vries JE, Roncarolo MG (1997) A CD4+ T-cell subset inhibits antigen-specific T-cell responses and prevents colitis. Nature 389: 737-742

24. Couper KN, Blount DG, Wilson MS, Hafalla JC, Belkaid Y, Kamanaka M, Flavell RA, de Souza JB, Riley EM (2008) IL10 from CD4CD25Foxp3CD127 adaptive regulatory $\mathrm{T}$ cells modulates parasite clearance and pathology during malaria infection. PLoS Pathog 4: e1000004.

25. de Araújo FF, Vitelli-Avelar DM, Teixeira-Carvalho A, Antas PR, Assis Silva Gomes J, Sathler-Avelar R, Otávio Costa Rocha M, Elói-Santos SM, Pinho RT, Correa-Oliveira R, Martins-Filho OA (2011) Regulatory T cells phenotype in different clinical forms of Chagas' disease. PLoS Negl Trop Dis 5: e992.

26. Rodrigues V, Cordeiro-da-Silva A, Laforge M, Ouaissi A, Akharid K, Silvestre R, \& Estaquier J. (2014). Impairment of T Cell Function in Parasitic Infections. PLoS Negl Trop Dis 8, e2567.

27. van Crevel R, Ottenhoff TH, van der Meer JW (2002).Innate immunity to Mycobacterium tuberculosis. Clin Microbiol Rev 15: 294-309

28. Fincham JE, Markus MB, Adams VJ (2003) Could control of soil-transmitted helminthic infection influence the HIV/AIDS pandemic. Acta Trop 86: 315-333.

29. Borkow G, Bentwich Z (2004) Chronic immune activation associated with chronic helminthic and human immunodeficiency virus infections: role of hyporesponsiveness and anergy. Clin Microbiol Rev 17: 10121030

30. Borkow G, Weisman Z, Leng Q, Stein M, Kalinkovich A, Wolday D, Bentwich Z (2001) Helminths, human immunodeficiency virus and tuberculosis. Scand J Infect Dis 33: $568-571$

31. Brown M, Miiro G, Nkurunziza P, Watera C, Quigley MA, Dunne DW, Whitworth JA, Elliott AM (2006) Schistosoma mansoni, nematode infections, and progression to active tuberculosis among HIV-1-infected Ugandans. Am J Trop Med Hyg 74: 819-825

32. Sarmiento C, Muñoz S, Rodriguez S, Ghisays G, Pastor D, Castillo O (2000) Technical standard for vaccination according to the expanded program of immunizations - PAI. General Directorate of Promotion and Prevention. Colombia: Ministry of Health. Available: https://www.minsalud.gov.co/sites/rid/Lists/BibliotecaDigital/ RIDE/VS/PP/1PAI.pdf. Accessed: 06 July 2017. [Article in Spanish]

33. Cooper PJ, Espinel I, Wieseman M, Paredes W, Espinel M, Guderian RH, Nutman TB. (1999). Human onchocerciasis and tetanus vaccination: impact on the postvaccination antitetanus antibody response. Infect Immun 67: 5951-5957

34. Cooper PJ, Chico M, Sandoval C, Espinel I, Guevara A, Levine MM, Griffin GE, Nutman T (2001) Human infection with Ascaris lumbricoides is associated with suppression of the interleukin-2 response to recombinant cholera toxin B subunit following vaccination with the live oral cholera vaccine CVD 103-HgR. Infect Immun 69: 1574-1580

35. Greenwood BM, Bradley-Moore AM, Bryceson AD, Palit A (1972) Immunosuppression in children with malaria. Lancet 1: $169-172$

36. Cumberland P, Shulman CE, Maple PA, Bulmer JN, Dorman EK, Kawuondo K, Marsh K, Cutts FT (2007) Maternal HIV infection and placental malaria reduce transplacental antibody transfer and tetanus antibody levels in newborns in Kenya. J Infect Dis 196: 550-557

37. Álvarez-Larrotta C, Agudelo OM, Duque Y, Gavina K, Yanow SK, Maestre A, Carmona-Fonseca J, Arango E Submicroscopic Plasmodium infection during pregnancy is associated with reduced antibody levels to tetanus toxoid. Clin Exp Immunol 2018. [Epub ahead of print].

38. Prost A, Schlumberger M, Fayet MT (1983) Response to tetanus immunization in onchocerciasis patients. Ann Trop Med Parasitol 77: 83-85

39. Nookala S, Srinivasan S, Kaliraj P, Narayanan RB, Nutman TB (2004) Impairment of tetanus-specific cellular and humoral responses following tetanus vaccination in human lymphatic filariasis. Infect Immun 72: 2598-2604

40. Malhotra I, McKibben M, Mungai P, McKibben E, Wang X, Sutherland LJ, Muchiri EM, King CH, King CL, LaBeaud AD (2015) Effect of antenatal parasitic infections on anti-vaccine IgG levels in children: a prospective birth cohort study in Kenya. PLoS Negl Trop Dis 9: e0003466.

41. Zwerling A, Behr MA, Verma A, Brewer TF, Menzies D, Pai $M$ (2011) The BCG world atlas: a database of global BCG vaccination policies and practices. PLoS Med 8 e1001012.

42. González-Fernández A, Faro J, Fernández C. (2008). Immune responses to polysaccharides: lessons from humans and mice. Vaccine 26: 292-300

43. Kelly DF, Thorson S, Maskey M, Mahat S, Shrestha U, Hamaluba M, Williams E, Dongol S, Werno AM, Portess H, Yadav BK, Adhikari N, Guiver M, Thomas K, Murdoch DR, Pollard AJ (2011). The burden of vaccine-preventable invasive bacterial infections and pneumonia in children admitted to hospital in urban Nepal. Int J Infect Dis 15: e17-e23

44. Belkaid Y (2008). Role of Foxp3-positive regulatory T cells during infection. Eur J Immunol 38: 918-921

45. Wherry EJ (2011) T cell exhaustion. Nat Immunol 12: 492-499

46. Schietinger A, Greenberg PD (2014) Tolerance and exhaustion: defining mechanisms of $\mathrm{T}$ cell dysfunction. Trends Immunol 35: 51-60

47. Gómez-Pérez GP, van Bruggen R, Grobusch MP, Dobaño C (2014) Plasmodium falciparum malaria and invasive bacterial co-infection in young African children: the dysfunctional spleen hypothesis. Malar J 13: 335

48. Mooney JP, Lokken KL, Byndloss MX, George MD, Velazquez EM, Faber F, Butler BP, Walker GT, Ali MM, Potts R, Tiffany C, Ahmer BM, Luckhart S, Tsolis RM (2015) Inflammation-associated alterations to the intestinal microbiota reduce colonization resistance against nontyphoidal Salmonella during concurrent malaria parasite infection. Sci Rep 5: 14603.

49. Corrigall RJ (1988) Asymptomatic malaria parasitaemia and the antibody response to tetanus toxoid vaccination. Trans $\mathrm{R}$ Soc Trop Med Hyg 82: 540-541

50. van Riet E, Adegnika AA, Retra K, Vieira R, Tielens AG, Lell B, Issifou S, Hartgers FC, Rimmelzwaan GF, Kremsner PG, Yazdanbakhsh M (2007) Cellular and humoral responses to influenza in gabonese children living in rural and semi-urban areas. J Infect Dis 196: 1671-1678

51. Elias D, Wolday D, Akuffo H, Petros B, Bronner U, Britton S (2001) Effect of deworming on human $T$ cell responses to mycobacterial antigens in helminth-exposed individuals before and after bacille Calmette-Guérin (BCG) vaccination. Clin Exp Immunol 123: 219-225

52. Lule SA, Mawa PA, Nkurunungi G, Nampijja M, Kizito D, Akello F, Muhangi L, Elliott AM, Webb EL (2015) Factors associated with tuberculosis infection, and with antimycobacterial immune responses, among five year olds BCGimmunised at birth in Entebbe, Uganda. Vaccine 33: 796-804 
53. Walther B, Miles DJ, Waight P, Palmero MS, Ojuola O, Touray ES, Whittle H, van der Sande M, Crozier S, Flanagan KL (2012) Placental malaria is associated with attenuated CD4 T-cell responses to tuberculin PPD 12 months after BCG vaccination. BMC Infect Dis 12: 6

54. Badawy AA, Yahya RS, Awad SI, Al-Sawah GA, Kizilbash NA (2013) Relationship between NRAMP1 gene polymorphism and efficacy of BCG vaccine in a helminthinfected population. Genet Mol Res 12: 3048-3056

55. Williamson WA, Greenwood BM (1978). Impairment of the immune response to vaccination after acute malaria. Lancet 1 : $1328-1329$

56. Greenwood BM, Bradley AK, Blakebrough IS, Whittle HC, Marshall TF, Gilles HM (1980) The immune response to a meningococcal polysaccharide vaccine in an African village. Trans R Soc Trop Med Hyg 74: 340-346

57. Usen S, Milligan P, Ethevenaux C, Greenwood B, Mulholland K (2000) Effect of fever on the serum antibody response of Gambian children to Haemophilus influenzae type b conjugate vaccine. Pediatr Infect Dis J 19: 444-449

58. Simondon F, Preziosi MP, Pinchinat S, Yam A, Chabirand L, Wassilak S, Pines E, Trape JF, Salomon H, Hoffenbach A (1999) Randomised study of the possible adjuvant effect of BCG vaccine on the immunogenicity of diphtheria-tetanusacellular pertussis vaccine in Senegalese infants. Eur J Clin Microbiol Infect Dis 18: 23-29

59. Brown J, Baisley K, Kavishe B, Changalucha J, Andreasen A, Mayaud P, Gumodoka B, Kapiga S, Hayes R, Watson-Jones D (2014) Impact of malaria and helminth infections on immunogenicity of the human papillomavirus-16/18 AS04adjuvanted vaccine in Tanzania. Vaccine 32: 611-

60. Brückner S, Agnandji ST, Berberich S, Bache E, Fernandes JF, Schweiger B, Loembe MM, Engleitner T, Lell B, Mordmüller B, Adegnika AA, Yazdanbakhsh M, Kremsner PG, Esen M (2015) Effect of Antihelminthic Treatment on Vaccine Immunogenicity to a Seasonal Influenza Vaccine in Primary School Children in Gabon: A Randomized Placebo-Controlled Trial. PLoS Negl Trop Dis 9: e0003768.

61. McGregor IA, Barr M. (1962). Antibody response to tetanus toxoid inoculation in malarious and non-malarious Gambian children. Transactions of the Royal Society of Tropical Medicine and Hygiene, 56: 364-367

62. Greenwood AM, Greenwood BM, Bradley AK, Ball PAJ, Gilles HM. (1981). Enhancement of the immune response to meningococcal polysaccharide vaccine in a malaria endemic area by administration of chloroquine. Annals of Tropical Medicine \& Parasitology, 75: 261-263

63. Monjour L, Bourdillon F, Schlumberger M, Fayet MT, Michon C, Ballet JJ, Gouba E, Gentilini M. (1982). [Humoral and cellular immunity following antitetanus vaccination in malnourished and malaria-induced African children. 1. Study of the antitetanus antibody response]. Bull World Health Organ 1982, 60: 589-596

64. Gilles HM, Greenwood BM, Greenwood AM, Bradley AK, Blakebrough I, Pugh RN, Musa B, Shehu U (1983) The Malumfashi project--an epidemiological, clinical and laboratory study. Trans $R$ Soc Trop Med Hyg 77: 24-31
65. Brabin BJ, Nagel J, Hagenaars AM, Ruitenberg E, van Tilborgh AM. (1984). The influence of malaria and gestation on the immune response to one and two doses of adsorbed tetanus toxoid in pregnancy. Bull World Health Organ, 62: 919-930

66. Schellenberg D, Menendez C, Kahigwa E, Aponte J, Vidal J, Tanner M, Mshinda H, Alonso P. (2001). Intermittent treatment for malaria and anaemia control at time of routine vaccinations in Tanzanian infants: a randomised, placebocontrolled trial. Lancet, 357: 1471-1477

67. Massaga JJ, Kitua AY, Lemnge MM, Akida JA, Malle LN, Rønn AM, Theander TG, Bygbjerg IC. (2003). Effect of intermittent treatment with amodiaquine on anaemia and malarial fevers in infants in Tanzania: a randomised placebocontrolled trial. Lancet, 361: 1853-1860

68. Rosen JB, Breman JG, Manclark CR, Meade BD, Collins WE, Lobel HO, Saliou P, Roberts JM, Campaoré P, Miller MA (2005) Malaria chemoprophylaxis and the serologic response to measles and diphtheria-tetanus-whole-cell pertussis vaccines. Malar J 4: 53

69. Cénac A, Develoux M, Djibo A. (1988). Chloroquine treatment of malaria does not increase antibody response to measles vaccination. A controlled study of 580 rural children living in an endemic malaria area. Trans R Soc Trop Med Hyg, 82: 405

70. Faucher J-F, Binder R, Missinou MA, Matsiegui P-B, Gruss H, Neubauer R, Lell B, Bertrand Lell, Que JU, Miller GB, Kremsner PG. Efficacy of Atovaquone/Proguanil for Malaria Prophylaxis in Children and Its Effect on the Immunogenicity of Live Oral Typhoid and Cholera Vaccines. Clinical Infectious Diseases 2002, 35: 1147-1154

71. World Health Organization. World Malaria Report; WHO: Geneva, Switzerland, 2015.K

72. Molyneux DH, Savioli L, Engels D (2016) Neglected tropical diseases: progress towards addressing the chronic pandemic. Lancet published online 6736(16)30171-4

73. World Health Organization (2016) Leishmaniasis in highburden countries: an epidemiological update based on data reported in 2014. In: Postigo/Leishmaniasis DJ 11.

74. World Health Organization (2016) Global programme to eliminate lymphatic filariasis: progress report, 2015. Wkly Epidemiol Rec 91(39):441-55.

75. World Health Organization (2016) Schistosomiasis: number of people treated worldwide in 2014. Wkly Epidemiol Rec 91: 5360.

\section{Corresponding author}

Catalina Álvarez Larrotta

Grupo Salud y Comunidad

Facultad de Medicina

Universidad de Antioquia

Kra51D \# 62-29, office 303.

Phone: +574 2196024

Fax: +574 2196000

Email: emarango@gmail.

Conflict of interests: No conflict of interests is declared. 